University of Nebraska - Lincoln

DigitalCommons@University of Nebraska - Lincoln

Agronomy \& Horticulture -- Faculty Publications

Agronomy and Horticulture Department

$5-1-2001$

\title{
Use of Remote-Sensing Imagery to Estimate Corn Grain Yield
}

\author{
J.F. Shanahan \\ University of Nebraska-Lincoln, jshanahan1@unl.edu \\ James S. Schepers \\ University of Nebraska-Lincoln, james.schepers@gmail.com \\ Dennis D. Francis \\ University of Nebraska-Lincoln \\ Gary E. Varvel \\ University of Nebraska-Lincoln, gevarvel@windstream.net \\ Wallace Wilhelm \\ University of Nebraska-Lincoln, wwilhelm1@unl.edu
}

See next page for additional authors

Follow this and additional works at: https://digitalcommons.unl.edu/agronomyfacpub

Part of the Plant Sciences Commons

Shanahan, J.F.; Schepers, James S.; Francis, Dennis D.; Varvel, Gary E.; Wilhelm, Wallace; Tringe, James M.; Schlemmer, Michael R.; and Major, David J., "Use of Remote-Sensing Imagery to Estimate Corn Grain Yield" (2001). Agronomy \& Horticulture -- Faculty Publications. 9.

https://digitalcommons.unl.edu/agronomyfacpub/9

This Article is brought to you for free and open access by the Agronomy and Horticulture Department at DigitalCommons@University of Nebraska - Lincoln. It has been accepted for inclusion in Agronomy \& Horticulture -Faculty Publications by an authorized administrator of DigitalCommons@University of Nebraska - Lincoln. 


\section{Authors}

J.F. Shanahan, James S. Schepers, Dennis D. Francis, Gary E. Varvel, Wallace Wilhelm, James M. Tringe, Michael R. Schlemmer, and David J. Major 
Nobel, P.S. 1988. Environmental biology of Agaves and Cacti. Cambridge Univ. Press, New York.

Palta, J.A., and P.S. Nobel. 1989. Influences of water status, temperature, and root age on daily patterns of root respiration for two cactus species. Ann. Bot. 63:651-662.

Passioura, J.B., and P.A. Gardner. 1990. Control of leaf expansion in wheat seedlings growing in drying soil. Aust. J. Plant Physiol. 17:149-157.

Penman, H.L. 1948. Natural evaporation from open water, bare soil, and grass. Proc. R. Soc. London., Ser. A. 193:120-145.

Radin, J.W. 1983. Control of plant growth by nitrogen: Differences between cereals and broadleaf species. Plant Cell Environ. 6:65-68.

Sadras, V.O., P.A. Calviño, and A. Bustamante. 1999. Variación interanual en el rendimiento de soja: III. Análisis de riesgo económico 1o Congreso de Soja del Mercosur. Asociación Argentina de la Soja, Rosario, Argentina.

Sadras, V.O., L. Echarte, and F.H. Andrade. 2000. Profiles of leaf senescence during reproductive growth of sunflower and maize. Ann. Bot. 85:187-195.
Sadras, V.O., and S.P. Milroy. 1996. Soil-water thresholds for the responses of leaf expansion and gas exchange. Field Crops Res. 47:253-266.

Sinclair, T., C. Tanner, and J. Bennett. 1984. Water-use efficiency in crop production. Bioscience 34:36-40.

Tollenaar, M., and L.M. Dwyer. 1999. Physiology of maize. p. 169-204. In D.L. Smith and C. Hammel (ed.) Crop yield: Physiology and processes. Springer-Verlag, Berlin, Germany.

Travasso, M.I., and E.E. Suero. 1994. Estimación de la capacidad de almacenaje de agua en suelos del sudeste bonaerense. Boletín Técnico 125. Estación Experimental Agropecuaria Balcarce, Argentina.

Uhart, S.A., and H.E. Echeverrría. 2000. Diagnóstico de la fertilización. p. 235-268. In F.H. Andrade and V.O. Sadras (ed.) Bases para el manejo del maíz, el girasol y la soja. INTA-Universidad de Mar del Plata, Balcarce, Argentina.

Vega, C.R.C., V.O. Sadras, F.H. Andrade, and S.A. Uhart. 2000. Reproductive allometry in soybean, maize, and sunflower. Ann. Bot. 85:461-468.

\title{
Use of Remote-Sensing Imagery to Estimate Corn Grain Yield
}

\author{
John F. Shanahan,* James S. Schepers, Dennis D. Francis, Gary E. Varvel, Wallace W. Wilhelm, \\ James M. Tringe, Mike R. Schlemmer, and David J. Major
}

\begin{abstract}
Remote sensing - the process of acquiring information about objects from remote platforms such as ground-based booms, aircraft, or satellites-is a potentially important source of data for site-specific crop management, providing both spatial and temporal information. Our objective was to use remotely sensed imagery to compare different vegetation indices as a means of assessing canopy variation and its resultant impact on corn (Zea mays L.) grain yield. Treatments consisted of five $\mathbf{N}$ rates and four hybrids, which were grown under irrigation near Shelton, NE on a Hord silt loam in 1997 and 1998. Imagery data with $0.5-\mathrm{m}$ spatial resolution were collected from aircraft on several dates during both seasons using a multispectral, four-band [blue, green, red, and near-infrared reflectance] digital camera system. Imagery was imported into a geographical information system (GIS) and then georegistered, converted into reflectance, and used to compute three vegetation indices. Grain yield for each plot was determined at maturity. Results showed that green normalized difference vegetation index (GNDVI) values derived from images acquired during midgrain filling were the most highly correlated with grain yield; maximum correlations were 0.7 and 0.92 in 1997 and 1998, respectively. Normalizing GNDVI and grain yield variability within hybrids improved the correlations in both years, but more dramatic increases were observed in $1997(0.7$ to 0.82$)$ than in $1998(0.92$ to 0.95$)$. This suggested GNDVI acquired during midgrain filling could be used to produce relative yield maps depicting spatial variability in fields, offering a potentially attractive alternative to use of a combine yield monitor.
\end{abstract}

$\mathrm{R}_{\mathrm{t}}$

MOTE SENSING - the process of acquiring information about objects from remote platforms such as

J.F. Shanahan, J.S. Schepers, D.D. Francis, G.E. Varvel, W.W. Wilhelm, J.M. Tringe, and M.R. Schlemmer, USDA-ARS and Dep. of Agron., Univ. of Nebraska, Lincoln, NE 68583; and D.J. Major, Resource21 LLC, Suite 206, 1410 Mayor Magrath Drive South, Lethbridge, AB, T1K 2R3 Canada. Joint contribution of the USDA-ARS and Agric. Res. Div. of the Univ. of Nebraska. Published as Journal Ser. no. 13302. Received 15 May 2000. *Corresponding author (jshanahan@unl.edu).

Published in Agron. J. 93:583-589 (2001). ground-based booms, aircraft, or satellites-is a potentially important source of data for site-specific crop management, providing spatial and temporal information (NRC, 1997). Obtaining temporal information that is detailed and spatially distributed from other site-specific crop management methods is difficult and expensive (NRC, 1997). Where available, remotely sensed images show spatial and spectral variations resulting from soil and crop characteristics. One potential advantage of remote-sensing imagery is that it is not limited by sampling interval or geostatistical interpolation, as has been implied for grid-sampled soil test data (Moran et al., 1997).

For more than $30 \mathrm{yr}$, remote sensing has been envisioned as a valuable source of information for crop management. The pioneering research of Colwell (1956) showed that infrared aerial photography could be used to detect loss of vigor from disease in wheat (Triticum aestivum L.) and other small grains. One of the earliest digital remote-sensing analysis procedures developed to identify the vegetation contribution in an image was the ratio vegetation index (RVI), created by dividing nearinfrared reflectance (NIR) by red reflectance (Jordan, 1969). The basis of this relationship is the strong absorption (low reflectance) of red light by chlorophyll and low absorption (high reflectance and transmittance) in the NIR by green leaves (Avery and Berlin, 1992). Dense green vegetation produces a high ratio while soil has a low value, thus yielding a contrast between the two surfaces.

Since the RVI, a number of vegetation indices have been developed and can be used to interpret aerial imagery (e.g., Wiegand et al., 1991). The normalized differ-

Abbreviations: DN, digital number; GIS, geographical information system; GNDVI, green normalized difference vegetation index; NDVI, normalized difference vegetation index; NIR, near-infrared reflectance; RVI, ratio vegetation index; TSAVI, transformed soil adjusted vegetation index. 
ence vegetation index $(\mathrm{NDVI})$, where NDVI $=(\mathrm{NIR}-$ Red)/(NIR + Red), was originally proposed as a means of estimating green biomass (Tucker, 1979). The basis for the relationship between NDVI and green biomass appears to be related to the amount of photosynthetically active radiation absorbed by the canopy (Sellers, 1985, 1987). The NDVI relates the reflectance in the red region (near chlorophyll $a$ absorption max.) and NIR region to vegetation variables such as leaf area index, canopy cover, and the concentration of total chlorophyll. Numerous researchers (Teillet, 1992; Wade et al., 1994; Ramsey et al., 1995; Roderick et al., 1996b; Roderick et al., 1996a) have utilized the NDVI, derived from advanced very high resolution radiometer (AVHRR) imagery collected from satellite platforms, to assess the health and condition of crops and natural vegetation over large geographical regions.

Other researchers have indicated, however, that NDVI may be inadequate for assessing crop vegetation due to confounding soil background effects in imagery and have suggested the use of indices such as soil-adjusted vegetation index (SAVI; Huete, 1988), optimized soiladjusted vegetation index (OSAVI; Rondeaux et al., 1996), and transformed soil-adjusted vegetation index (TSAVI; Baret et al., 1989). Alternatively, Gitelson et al. (1996) proposed use of the green normalized difference vegetation index (GNDVI) (where the green band is substituted for the red band in the NDVI equation), which may prove to be more useful for assessing canopy variation in green crop biomass. Thus, there appears to be a number of indices that might be useful for estimating crop biomass and ultimately grain yield.

Our objectives were to use remotely sensed imagery to compare three vegetation indices (NDVI, TSAVI, and GNDVI) as a means of assessing canopy variation and estimating final grain yield for corn and to determine how normalizing treatment vegetation indices and grain yields may affect their associations.

\section{MATERIALS AND METHODS}

\section{Experimental Treatments and Field Design}

The study was conducted near Shelton, NE $\left(40^{\circ} 45^{\prime} 01^{\prime \prime} \mathrm{N}\right.$, $98^{\circ} 46^{\prime} 01^{\prime \prime} \mathrm{W}$; elevation, $620 \mathrm{~m}$ above mean sea level) during the 1997 and 1998 growing seasons. The soil at this site is a Hord silt loam (fine-silty, mixed mesic Pachic Haplustoll). The crop was grown under conventional tillage practices with a sprinkler irrigation system. Field plots used in this work were part of an ongoing study (1991-present) involving treatment combinations of four Pioneer hybrids ('3162', '3379', '3394', and ' 3417 ') and five $\mathrm{N}$ application levels $(0,50,100,150$, and $200 \mathrm{~kg} \mathrm{~N} \mathrm{ha}^{-1}$ ). A split plot arrangement of treatments was used with hybrids as main plots, $\mathrm{N}$ levels as subplots, and four replications in a randomized complete block design. Because hybrid and $\mathrm{N}$ treatments had been applied to the same areas from the beginning of the original study, residual soil $\mathrm{N}$ levels were low in the control plots $\left(0 \mathrm{~kg} \mathrm{~N} \mathrm{ha}^{-1}\right)$, and crop response to $\mathrm{N}$ was assured in these plots. Hybrids were selected because of their differences in maturity and canopy architecture (upright architecture for 3394 vs. planophile orientation for the other hybrids). The comparative relative maturity for the hybrids were as follows: 3162, 118; 3379 and 3394, 113; and 3417,
$109 \mathrm{~d}$. Individual plot dimensions were 7.3 by $15.2 \mathrm{~m}$, consisting of eight $0.91-\mathrm{m}$ rows planted in an east to west direction.

The research plots were planted during the last week of April in both seasons at a seeding density of approximately 74000 seeds $\mathrm{ha}^{-1}$. Liquid fertilizer (10-34-0) was applied in the furrow at planting at the rate of $94 \mathrm{~L} \mathrm{ha}^{-1}$, providing approximately $18 \mathrm{~kg} \mathrm{P} \mathrm{ha}{ }^{-1}$. Nitrogen fertilizer, as ammonium nitrate $\left(\mathrm{NH}_{4} \mathrm{NO}_{3}\right)$, was hand-applied when the crop reached the V4 growth stage (Ritchie et al., 1997). The crop received irrigation throughout the growing season (274 $\mathrm{mm}$ in 1997 and $129 \mathrm{~mm}$ in 1998) according to established irrigation-scheduling principles. Weed control during both growing seasons was accomplished through a combination of cultivation and herbicide application. Climatological data were recorded for both growing seasons through the use of an automated weather station (High Plains Climate Cent. Network, Univ. of Nebraska) located on the research site. Phenology data according to Ritchie et al. (1997) were recorded weekly from the 1 June through mid-August.

\section{Imagery Acquisition, Calibration, and Conversion to Reflectance}

Digital remotely sensed imagery data were collected for the entire plot area on several dates during both growing seasons, beginning in June and ending in early September. Imagery was acquired near midday [within $3 \mathrm{~h}( \pm)$ of solar noon] under cloud-free conditions with a four-band digital camera system mounted in an aircraft at an altitude of $1000 \mathrm{~m}$. In 1997, a SpecTerra Mark III (SpecTerra, Perth, WA, Australia) mounted in a Resource21 (Englewood, CO) Cessna 180 (Wichita, KS) aircraft, was used to acquire images. In 1998, a Resource21 sensor utilizing a Vision One sensor (Vision One, Bozeman, MT) mounted in a Hauts Monts (Quebec City, QC, Canada) Cessna Conquest II aircraft, was used to acquire images. Both sensors were four-band, multispectral scanning instruments. The four bands used were: blue (450$520 \mathrm{~nm})$, green $(520-600 \mathrm{~nm})$, red (630-680 nm), and NIR (775-900 nm). Data output of the Mark III and Vision One sensors was 8-bit and 12-bit digital, respectively. Hence, the 1998 sensor system was potentially 16 times more sensitive than the 1997 system. The nominal spatial ground resolution was about $0.5 \mathrm{~m}$ for both sensors.

Four targets (1.2-by 2.4-m wood sheets painted white) were placed at the corners of the research plot area to assist with georegistering the image. Geological coordinates were obtained for the targets with a DGPS receiver (Model 124, Trimble, Sunnyvale, CA) for use in the image georegistration process. For the purposes of imagery radiometric calibration, four 8- by 8 -m tarps (BAE Systems, Austin, TX) with factorysuggested reflective values of $4,8,48$, and $64 \%$ were placed near the experiment on each date just before image acquisition. Because tarp reflectance is known to vary with solar zenith angles and tarp dirtiness, tarp reflectance values were corrected throughout both growing seasons using the procedures of Jackson et al. (1992). They showed that reflectance from a Spectralon reference material (Spectralon, Labsphere, North Sutton, NH) could be described with a fourth-order equation:

$$
\rho=a_{0}+a_{1} \theta+a_{2} \theta^{2}+a_{3} \theta^{3}+a_{4} \theta^{4}
$$

where $\rho$ is reflectance, $\theta$ is the solar zenith angle, $a_{0}$ is a term that accounts for the spectral properties of the material, and $a_{1}$ through $a_{4}$ are polynomial coefficients. In-season nadir measurements of reflectance of the four tarps were periodically made throughout the season using a boom-mounted FieldSpec FR hyperspectral radiometer (Analytical Spectral Devices, 
Boulder, CO) at a height of $11 \mathrm{~m}$ above the tarps and a Spectralon reference panel to estimate $a_{0}$. Hyperspectral data collected from field calibrations during 1997 and 1998 were also used to determine the $a_{1}$ through $a_{4}$ coefficients. By calculating the reflectance of the tarps as a function of day-of-year (tarp dirtiness) and solar zenith angle, accurate tarp reflectance values were calculated for the time and day of image acquisition in both growing seasons.

Digital imagery data for the four bands were georegistered using TNTmips (MicroImages, Lincoln, NE) image-processing software. Images for the four bands were overlaid, and an area of interest was identified that corresponded to each plot (boundary minus border), leaving approximately 100 pixels for each plot. The areas of interest were used to extract the mean digital number (DN) representing each band for each plot.

The sensor DN values were converted to units of reflectance (ratio of reflected to incident radiation flux, ranging from $0-1$ ) using a linear calibration equation specific for each band and date. The slope and intercept of the equations were derived by regressing corrected tarp reflectance values vs. DNs extracted from images for each tarp and date. Because each image had four tarps of known calibrated reflectance in the scene, the regression equations utilized at least two and up to four tarps, depending on whether or not the image was saturated in a given band. The coefficient of determination for each calibration equation always exceeded 0.95 . Using these linear equations, DN output extracted from the images was converted into reflectance for each plot.

\section{Conversion of Reflectance Data to Vegetation Indices}

Values for NDVI, TSAVI, and GNDVI were calculated using reflectance values for the appropriate bands. The NDVI equation was presented previously. The TSAVI equation was published by Baret et al. (1989):

$$
\begin{aligned}
\text { TSAVI }= & a[\mathrm{NIR}-(a \times \mathrm{Red})-b] /[\mathrm{Red} \\
& +(a \times \mathrm{NIR})-(a \times b)]
\end{aligned}
$$

where the $a$ and $b$ values represent the slope and intercept, respectively, of an equation fitted through a plot of red vs. NIR reflectance data for a variety of bare soil conditions (dry, wet, smooth, and rough). To evaluate the $a$ and $b$ values for local calibration, a combination of bare soil conditions were created near our experiment in both years using tillage to vary surface roughness and drying of the soil surface after precipitation or irrigation events to vary soil wetness. Hyperspectral readings were collected from these various soil conditions (about 20 combinations of soil roughness and wetness) in both years. The $a$ and $b$ values agreed closely for both years $\left(r^{2}=0.85\right)$ and with the published values of Baret et al. (1989), providing justification for the use of their $a$ and $b$ values in our work

The GNDVI equation was developed by Gitelson et al. (1996):

$$
\text { GNDVI }=(\text { NIR }- \text { Green }) /(\text { NIR }+ \text { Green })
$$

\section{Leaf Chlorophyll Content Assessment}

To assess variation in leaf chlorophyll content, readings were collected with the model 502 Minolta SPAD meter (Spectrum Technologies, Plainfield, IL) per Blackmer and Schepers (1995) at approximately weekly intervals during both growing seasons, starting at the V6 growth stage and continuing to the R3 stage (nine and eight dates in 1997 and 1998, respectively).
Readings were collected before silking from the most recent fully expanded leaf (visible collar), and after silking, the ear leaf was sampled. Measurements were taken midway between the leaf tip and base and midway between the leaf margin and midrib from 30 representative plants selected from the center two rows of each plot. These measurements were then averaged for each plot. Damaged plants or those unusually close together or far apart were not sampled.

\section{Harvest Procedures and Statistical Analysis}

At maturity, three of the center four rows were machineharvested to determine grain yield. Grain yields were adjusted to a constant moisture basis of $155 \mathrm{~g} \mathrm{~kg}^{-1}$ water. Grain yield, vegetation index, and chlorophyll meter data were analyzed via ANOVA with a mixed model, using the SAS PROC MIXED procedure (Littel et al., 1996). For the yield data, hybrids and $\mathrm{N}$ treatments were considered fixed effects, and blocks were considered random effects. For the vegetation indices and chlorophyll meter data, the analysis was the same, except imagery dates were included in the model and considered as repeated observations. Linear correlation analysis was used to determine the association between the different vegetation indices at each date and final grain yield.

\section{RESULTS AND DISCUSSION Treatment Effects on Grain Yield}

Average grain yields were approximately $20 \%$ lower in 1998 than in 1997 (Table 1). An evaluation of the climatological data revealed unusually cool $\left(2.8^{\circ} \mathrm{C}\right.$ cooler than avg.) and cloudy conditions ( $42 \%$ less solar radiation than normal) during the last 2 wk of July 1998,

Table 1. Response of grain yield and relative grain yield of four

\begin{tabular}{|c|c|c|c|c|c|}
\hline \multirow[b]{2}{*}{ Pioneer brand hybrid } & \multirow[b]{2}{*}{$\mathbf{N}$ rate } & \multicolumn{2}{|c|}{ Grain yield } & \multicolumn{2}{|c|}{$\begin{array}{c}\text { Relative grain } \\
\text { yield } \dagger\end{array}$} \\
\hline & & 1997 & 1998 & 1997 & 1998 \\
\hline & $\operatorname{kg} \mathbf{N} \mathbf{h a}^{-1}$ & - Mg & $\mathrm{ha}^{-1}$ & - & \\
\hline \multirow[t]{5}{*}{3162} & 0 & 11.0 & 6.9 & 83 & 63 \\
\hline & 50 & 13.3 & 9.6 & 101 & 87 \\
\hline & 100 & 13.8 & 12.3 & 105 & 112 \\
\hline & 150 & 14.2 & 13.4 & 108 & 122 \\
\hline & 200 & 13.7 & 12.7 & 104 & 116 \\
\hline \multirow[t]{5}{*}{3379} & 0 & 11.0 & 6.8 & 90 & 70 \\
\hline & 50 & 11.8 & 8.7 & 96 & 90 \\
\hline & 100 & 12.7 & 10.6 & 104 & 109 \\
\hline & 150 & 12.7 & 10.9 & 104 & 112 \\
\hline & 200 & 13.1 & 11.6 & 107 & 119 \\
\hline \multirow[t]{5}{*}{3394} & 0 & 10.6 & 6.2 & 87 & 66 \\
\hline & $\mathbf{5 0}$ & 11.7 & 8.4 & 96 & 89 \\
\hline & 100 & 12.6 & 10.1 & 104 & 107 \\
\hline & 150 & 12.8 & 11.3 & 106 & 119 \\
\hline & 200 & 13.0 & 11.5 & 107 & 121 \\
\hline \multirow[t]{5}{*}{3417} & 0 & 11.2 & 6.5 & 88 & 62 \\
\hline & $\mathbf{5 0}$ & 12.5 & 10.0 & 98 & 97 \\
\hline & 100 & 12.9 & 11.6 & 101 & 112 \\
\hline & 150 & 13.7 & 11.6 & 108 & 112 \\
\hline & 200 & 13.4 & 11.9 & 105 & 115 \\
\hline \multirow[t]{2}{*}{ Avg. } & & 12.6 & 10.1 & 100 & 100 \\
\hline & \multicolumn{3}{|c|}{ ANOVA } & & \\
\hline Source & df & 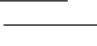 & Probabil & ity of $>F$ & 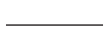 \\
\hline Hybrid & 3 & 0.0774 & 0.0572 & 1.0000 & 1.0000 \\
\hline & 4 & 0.0001 & 0.0001 & 0.0001 & 0.0001 \\
\hline Hybrid $\times \mathbf{N}$ & 12 & 0.5849 & 0.0877 & 0.7307 & 0.3079 \\
\hline
\end{tabular}
corn hybrids to five $\mathbf{N}$ rates during the 1997 and 1998 growing seasons at Shelton, NE.

$\dagger$ Relative to the average grain yield within each hybrid within each growing season. 

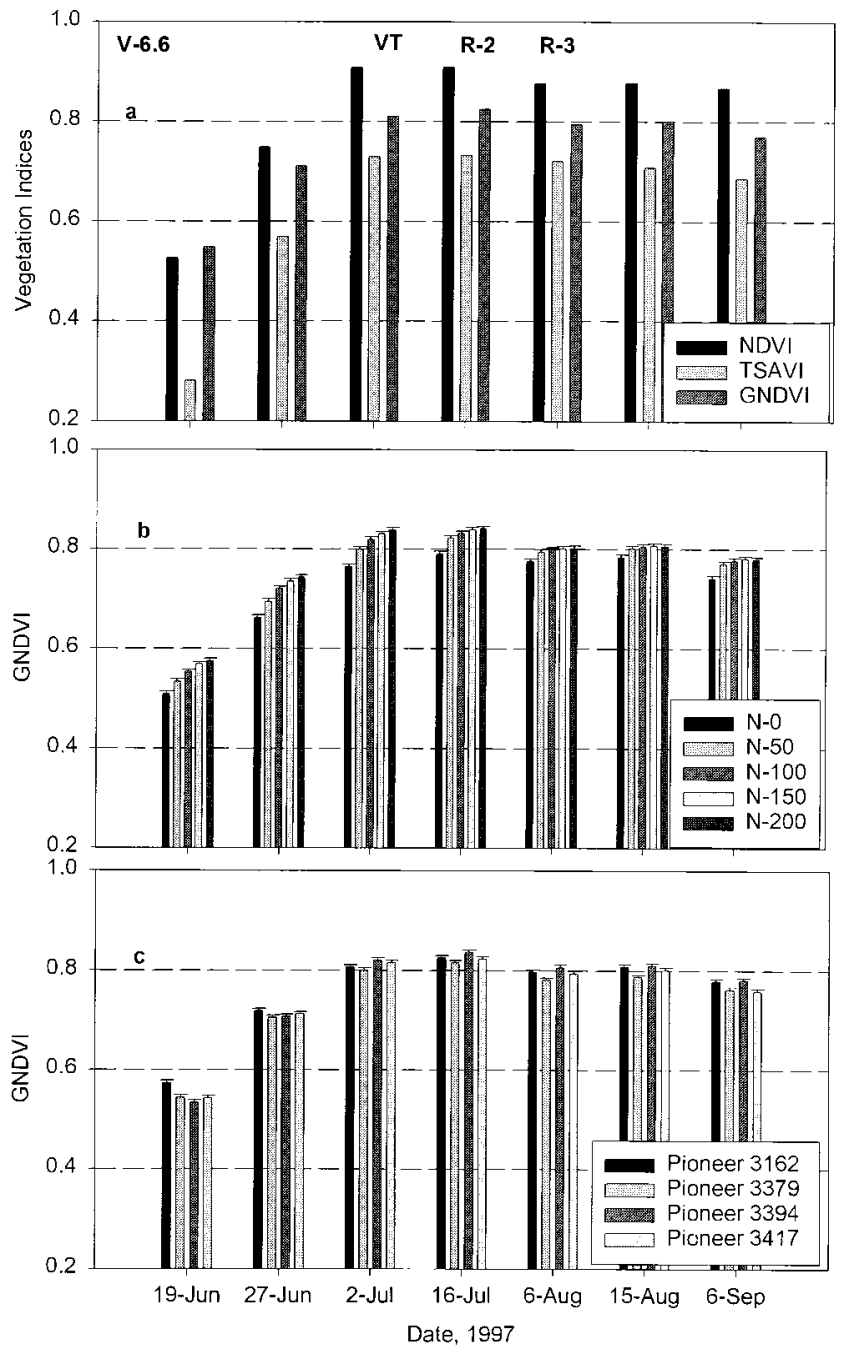

Fig. 1. (a) The response of three vegetation indices [normalized difference vegetation index (NDVI), transformed soil adjusted vegetation index (TSA VI), and green normalized difference vegetation index (GNDVI)] vs. seven dates of image acquisition, and the effect of $(b) \mathrm{N}$ and $(c)$ hybrids on GNDVI for the 1997 growing season. Important phenological dates for the average of all hybrid and $\mathbf{N}$ treatments are also depicted. Standard error values are shown to compare $\mathbf{N}$ and hybrid main effects vs. date.

which coincided with silking and flowering stages of crop development. The reduced solar irradiance in late July of 1998 very likely diminished crop photosynthesis and assimilation rates during critical reproductive development stages, resulting in decreased grain yields. The apexes of ears produced in 1998 were observed to have reduced kernel set, which is indicative of a stress during reproductive growth (Andrade et al., 2000) that adversely affected seed set.

The hybrid $\times \mathrm{N}$ interaction for grain yield was significant only in 1998, at $P \leq 0.0877$ (Table 1), suggesting that the hybrids used in this study respond similarly to applied N, which is similar to yield responses observed in a previous study involving these same treatments and plots from 1991 through 1995 (Varvel et al., 1997). The hybrid and $\mathrm{N}$ main effects were significant in both seasons, and hybrid 3162 (the full season hybrid) produced slightly higher grain yields than the other hybrids in both

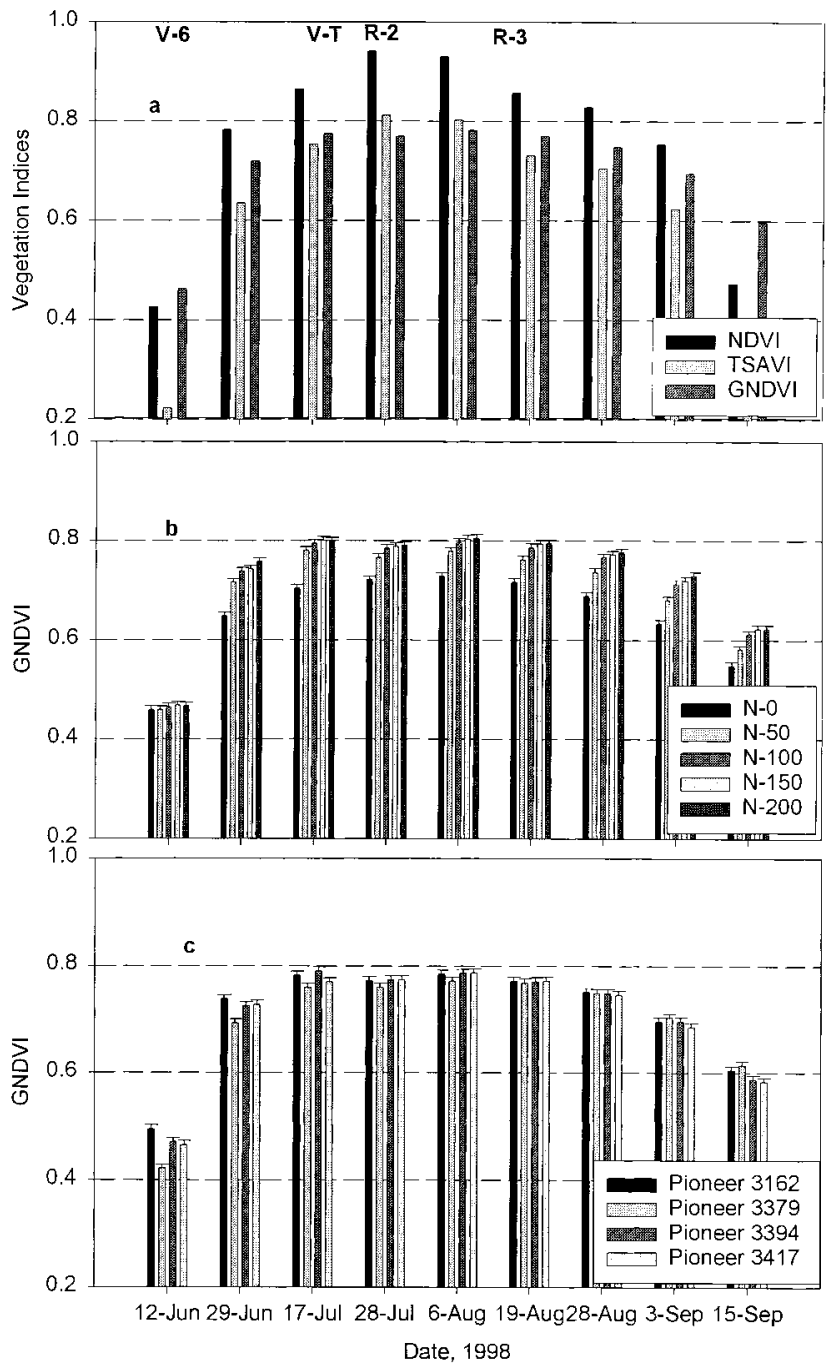

Fig. 2. (a) The response of three vegetation indices [normalized difference vegetation index (NDVI), transformed soil adjusted vegetation index (TSAVI), and green normalized difference vegetation index (GNDVI)] vs. nine dates of image acquisition, and the effect of $(b) \mathrm{N}$ and $(c)$ hybrids on GNDVI for the 1998 growing season. Important phenological dates for the average of all hybrid and $\mathbf{N}$ treatments are also depicted. Standard error values are shown to compare $\mathbf{N}$ and hybrid main effects vs. date.

years of the study. To evaluate relative yield response to $\mathrm{N}$ for each hybrid, grain yields were normalized by converting yield observations within a given hybrid to a percent of average yields for all $\mathrm{N}$ levels and replicates. This process, as expected, eliminated hybrid and hybrid $\times \mathrm{N}$ interaction effects but maintained the $\mathrm{N}$ effect in both seasons during which $\mathrm{N}$ application increased grain yields around 10 and $20 \%$, respectively, in 1997 and 1998 (Table 1).

\section{Treatment Effects on Vegetation Indices}

Vegetation indices were calculated from imagery data acquired on seven dates in 1997 and nine dates in 1998. To compare values for the three indices, data were averaged across all treatments and plotted vs. date of image acquisition (Fig. 1a and 2a). In both years, values for all three indices increased from the first date of image 
Table 2. Analysis of variance of three vegetation indices [normalized difference vegetation index (NDVI), transformed soil adjusted vegetation index (TSAVI), and green normalized difference vegetation index (GNDVI)] calculated from remotely sensed imagery data collected over four corn hybrids and five N levels during the 1997-1998 growing seasons at Shelton, NE.

\begin{tabular}{|c|c|c|c|c|c|c|c|}
\hline \multirow[b]{2}{*}{ Source of variation } & \multirow[b]{2}{*}{ df } & \multicolumn{3}{|c|}{1997 Vegetation indices } & \multicolumn{3}{|c|}{1998 Vegetation indices } \\
\hline & & NDVI & TSAVI & GNDVI & NDVI & TSAVI & GNDVI \\
\hline & & & & Prob & $>\boldsymbol{F}$ & & 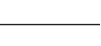 \\
\hline Hybrid & 3 & 0.0191 & 0.0001 & 0.0002 & 0.1017 & 0.0359 & 0.0114 \\
\hline $\mathbf{N}$ & 4 & 0.0001 & 0.0001 & 0.0001 & 0.0001 & 0.0001 & 0.0001 \\
\hline $\mathbf{N} \times$ hybrid & 12 & 0.9619 & 0.8519 & 0.9038 & 0.9882 & 0.9887 & 0.9380 \\
\hline Date & $6(8) \dagger$ & 0.0001 & 0.0001 & 0.0001 & 0.0001 & 0.0001 & 0.0001 \\
\hline Hybrid $\times$ date & $18(24)$ & 0.0001 & 0.0001 & 0.0001 & 0.0001 & 0.0001 & 0.0001 \\
\hline $\mathbf{N} \times$ date & $24(32)$ & 0.0001 & 0.0001 & 0.0001 & 0.0001 & 0.0001 & 0.0001 \\
\hline $\mathbf{N} \times$ hybrid $\times$ date & 72 (96) & 0.9225 & 0.9894 & 0.8899 & 0.9667 & 0.9098 & 1.0000 \\
\hline
\end{tabular}

$\dagger$ The values of degrees of freedom in parentheses are for the 1998 study.

acquisition, peaking around tasseling, and declined thereafter. The NDVI values generally exceeded the other two indices during most of the period that imagery was acquired in both growing seasons.

The ANOVA for the vegetation indices (Table 2) indicated that all three indices responded similarly to the treatment variables. For example, the hybrid $\times \mathrm{N}$ rate and hybrid $\times N$ rate $\times$ date sources of variation were nonsignificant while the hybrid $\times$ date and $\mathrm{N}$ rate $\times$ date terms were significant for all indices during both seasons. Similarly, the hybrid, $\mathrm{N}$ rate, and date main effects were also consistently significant for all three indices during both years.

Because all indices responded similarly to the treatments, only the GNDVI values are presented (Fig. 1b and $2 \mathrm{~b}$ ) to illustrate treatment effects on the indices. The effect of $\mathrm{N}$ levels on GNDVI values was apparent throughout the majority of both growing seasons (Fig. $1 \mathrm{~b}$ and $2 \mathrm{~b}$ ) during which the highest $\mathrm{N}$ level produced a maximum increase in GNDVI values of approximately $20 \%$ compared with the control $\mathrm{N}$ treatments. While the hybrid effect was less pronounced than the $\mathrm{N}$ effect (Fig. 1c and 2c), it was nonetheless significant in both seasons and similar to grain yield trends (Table 2) with 3162 maintaining slightly greater values than the other hybrids, particularly during early growth. In summary, the hybrid and $\mathrm{N}$ treatments used in our work generated a considerable amount of variation in both grain yield and vegetation indices.

\section{Association of Vegetation Indices with Grain Yield}

To explore the association between vegetation indices and absolute grain yields throughout both seasons, vegetation index values derived for each plot and imagery date were correlated with their respective grain yields (Fig. 3a and 4a). In general, correlations between vegetation indices and absolute grain yields were slightly higher in 1998 than in 1997. This difference was likely due to the greater sensitivity of the 1998 sensor used in our measurements (see methods) compared with that of 1997.

The pattern of association among the three vegetation indices and absolute grain yields varied slightly between the two growing seasons. In 1997, correlation values for associations between grain yields and NDVI and TSAVI were low early and then increased, peaking around tas- seling, and declining thereafter. With the GNDVI, correlation values were relatively constant for all dates. The early season pattern in 1998 was similar to 1997 , but unlike 1997, correlation values in 1998 declined for a short period after tasseling and then increased to their maximum values during the early to midgrain fill period. It is difficult to speculate on what caused the association between GNDVI and grain yield to decline temporarily after tasseling in 1998 while this was not observed in 1997. Perhaps it can be attributed to a combination of the use of a more sensitive sensor along with the presence of newly initiated tassels in the image scene (with no chlorophyll), which may have in turn temporarily
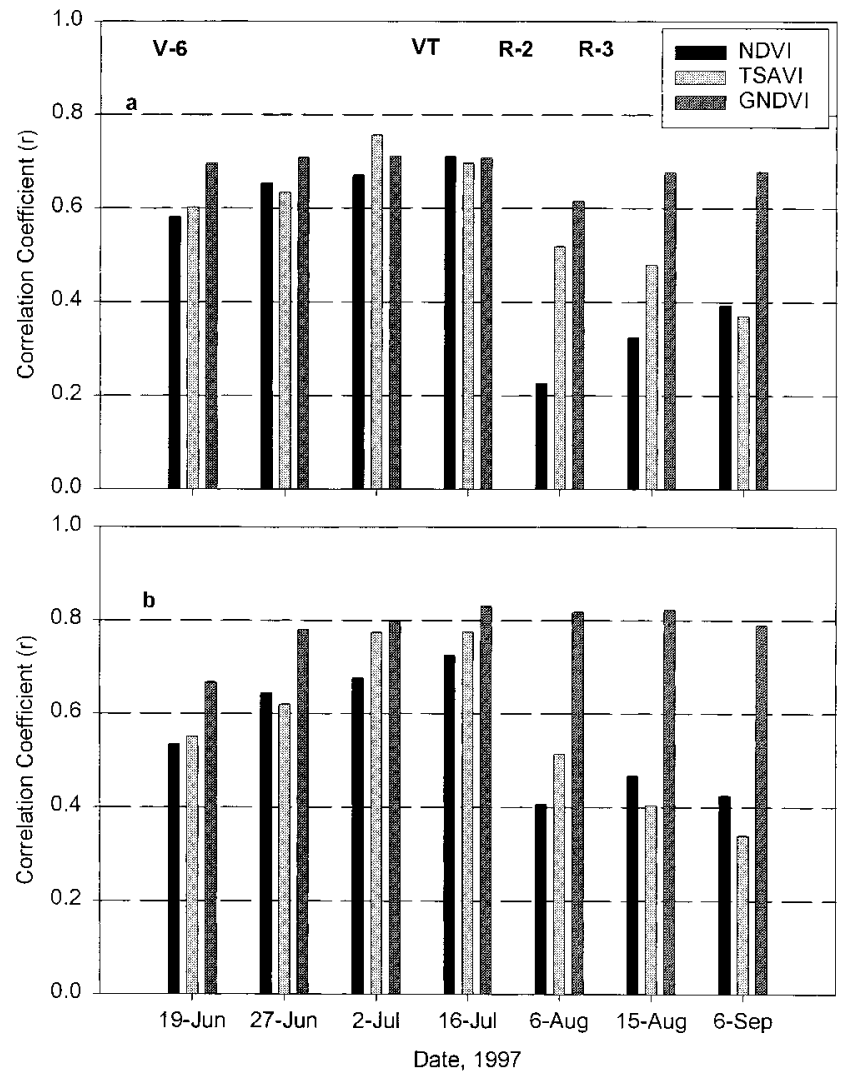

Fig. 3. Correlation coefficient values for $(a)$ the association of absolute vegetation indices vs. final grain yield for seven dates in the 1997 season and for $(b)$ normalized vegetation indices and grain yield. Important phenological dates for the average of all hybrid and $\mathrm{N}$ treatments are also depicted. Correlation values of $\mathbf{0 . 2 1 7}$ and 0.283 are significant at the 0.05 and 0.01 levels, respectively. 

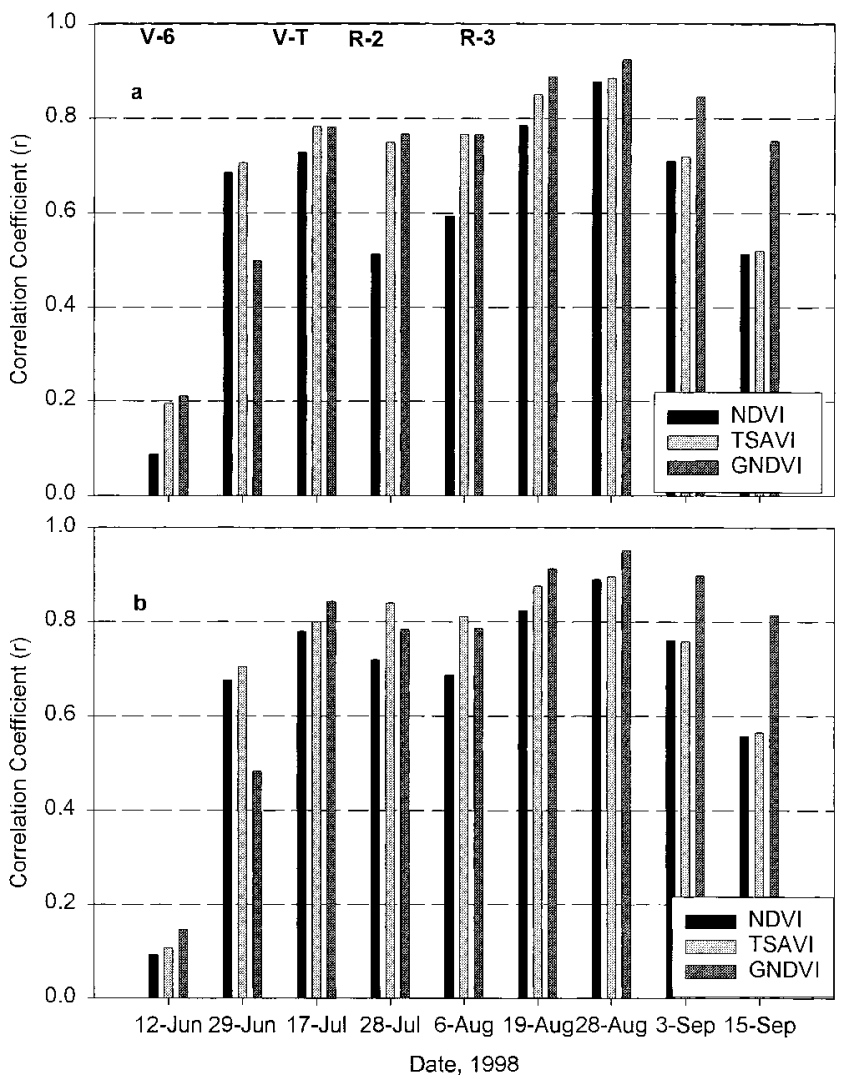

Fig. 4. Correlation coefficient values for $(a)$ the association of absolute vegetation indices vs. final grain yield for nine dates in the 1998 season and for $(b)$ normalized vegetation indices and grain yield. Important phenological dates for the average of all hybrid and $\mathrm{N}$ treatments are also depicted. Correlation values of 0.217 and 0.283 are significant at the 0.05 and 0.01 levels, respectively.

interfered with an accurate assessment of photosynthetically active vegetation. Regardless, during both seasons, the GNDVI values consistently produced the highest correlations with grain yield during midgrain filling with values approaching 0.70 and 0.92 in 1997 and 1998, respectively. This suggests that GNDVI values obtained during this growth stage would have the greatest potential for estimating final grain yields.

To date, few studies have been conducted attempting to relate GNDVI to grain yield of agricultural crops. However, previous work has shown an association between NDVI values and crop biomass accumulation, leaf area index, leaf chlorophyll levels, and photosynthetically active radiation absorbed by the canopy (Tucker, 1979; Sellers, 1985, 1987), which has in turn been associated with crop yield (Wiegand et al., 1994; Aparicio et al., 2000). However, when chlorophyll content, vegetation fraction, or leaf area index reach moderate to high values, NDVI (the red band) is apparently less sensitive to these biophysical parameters (Buschmann and Nagel, 1993; Gitelson and Merzlyak, 1994; Aparicio et al., 2000). Gitelson et al. (1996) have proposed that, under these conditions, the green band (GNDVI) is more sensitive than the red band (NDVI or TSAVI) in detecting leaf chlorophyll variation. The ANOVA for the chlorophyll meter data (Table 3) revealed significant hybrid and $\mathrm{N}$ treatment effects in both
Table 3. Analysis of variance of leaf chlorophyll assessments collected from four corn hybrids at five $\mathbf{N}$ levels with a Minolta SPAD meter during the 1997-1998 growing seasons at Shelton, NE.

\begin{tabular}{lclc}
\hline Source of variation & df & \multicolumn{1}{c}{1997} & 1998 \\
\hline & & - Probability & of $>\boldsymbol{F}-$ \\
Hybrid & 3 & 0.0001 & $\mathbf{0 . 0 0 0 4}$ \\
$\mathbf{N}$ & 4 & $\mathbf{0 . 0 0 0 1}$ & $\mathbf{0 . 0 0 0 1}$ \\
$\mathbf{N} \times$ hybrid & $\mathbf{1 2}$ & $\mathbf{0 . 4 6 6 3}$ & $\mathbf{0 . 1 3 4 0}$ \\
Date & $\mathbf{8}(7) \dagger$ & $\mathbf{0 . 0 0 0 1}$ & $\mathbf{0 . 0 0 0 1}$ \\
Hybrid $\times$ date & $\mathbf{2 4}(\mathbf{2 1 )}$ & $\mathbf{0 . 0 2 8 4}$ & $\mathbf{0 . 0 0 0 5}$ \\
$\mathbf{N} \times$ date & $\mathbf{3 2}(\mathbf{2 8 )}$ & $\mathbf{0 . 5 7 0 9}$ & $\mathbf{0 . 0 0 0 1}$ \\
$\mathbf{N} \times$ hybrid $\times$ date & $\mathbf{9 6}(\mathbf{8 4})$ & $\mathbf{1 . 0 0 0 0}$ & $\mathbf{1 . 0 0 0 0}$ \\
\hline
\end{tabular}

$\dagger$ The values of degrees of freedom in parentheses are for the 1998 study.

growing seasons. For example, $\mathrm{N}$ application increased meter values up to $20 \%$ relative to the control (data not shown), implying that the treatments created substantial variability in leaf chlorophyll content. Apparently, the GNDVI was more sensitive than the other two indices in detecting this variability, as suggested by Gitelson et al. (1996). Indeed, a considerable amount of research with remote sensing of corn canopies (Blackmer et al., 1994; Schepers et al., 1992; Schepers et al., 1996) has shown that the green band (in combination with the NIR band) is more highly associated with variability in leaf chlorophyll, $\mathrm{N}$ content, and grain yield than the red band.

These results demonstrate that many factors can potentially affect vegetation indices, including date of image acquisition as well as hybrid and $\mathrm{N}$ treatments (Table 2). Previous research (Schepers et al., 1992; Schepers, 1994; Peterson et al., 1993) with the chlorophyll meter reported similar results regarding the effects of several factors (e.g., hybrid, stages of growth, environment conditions, and plant disease) on assessments of corn leaf chlorophyll for $\mathrm{N}$ management. Because chlorophyll meter readings can be affected by so many factors, it has been suggested (Schepers et al., 1992; Schepers, 1994; Peterson et al., 1993) that readings should be normalized to an adequately $\mathrm{N}$-fertilized reference strip in each field and for each hybrid. Hence, we employed a similar strategy with the imagery data in this study. Grain yields (Table 1) and vegetation indices were normalized by converting absolute values to a percent of the average value across $\mathrm{N}$ levels and replications within a given hybrid. Correlations of normalized indices with normalized grain yields were improved on nearly all dates and in both seasons relative to the unstandardized data (Fig. 3b and 4b). For example, in 1997, correlation values increased from 0.7 to 0.82 during midgrain filling. While the increase in correlation values was not as dramatic in 1998 as in 1997, there was nonetheless a slight increase in correlation values of normalized data, especially for the final four dates during which the highest value increased from 0.92 to 0.95 (Fig. $4 \mathrm{a}$ and $4 \mathrm{~b}$ ). Thus, normalizing the data standardized the variability in vegetation indices and grain yields created by our treatment variables (especially hybrid effect) and improved their associations. This response was similar to results observed with the chlorophyll meter (Schepers et al., 1992; Schepers, 1994; Peterson et al., 1993). 


\section{SUMMARY AND CONCLUSIONS}

In summary, our work showed that use of the GNDVI derived from remotely sensed imagery of corn canopies, particularly during midgrain filling, was highly correlated with grain yield. Normalizing GNDVI and yield variability improved this association. It should be noted that use of the GNDVI for estimating corn grain yield was evaluated only under the unique environmental conditions present in this research. Thus, further validation of the use of this vegetation index under more diverse environmental conditions is needed to warrant it's widespread use. If proven to be reliable, GNDVI values generated from imagery data could prove useful in producing relative yield maps that depict spatial variability in fields before harvest while there is still time to examine the growing crop for cause and effect relationships. These relative yield maps, in conjunction with other GIS information layers, could facilitate variable application of certain crop inputs using site-specific management tools. The remotely sensed relative yield maps may offer an attractive alternative to the use of a combine yield monitor, which requires a DGPS receiver, calibration, and maintenance. Additionally, remotely sensed yield maps would not be affected by the inaccuracies (problems connected with grain flow dynamics and accurate logging of geographical position) associated with combine yield monitors, as has been suggested by Lark et al. (1997) and Arslan and Colvin (1999).

\section{ACKNOWLEDGMENTS}

Contributions of imagery and associated equipment through Cooperative Research and Development Agreement 58-3K957-544 between USDA-ARS and Resource 21 is gratefully acknowledged.

\section{REFERENCES}

Andrade, F.H., M.E. Otegui, and C. Vega. 2000. Intercepted radiation at flowering and kernel number in maize. Agron. J. 92:92-97.

Aparicio, N., D. Villegas, J. Casadesus, J.L. Araus, and C. Royo. 2000. Spectral vegetation indices as nondestructive tools for determining durum wheat yield. Agron. J. 92:83-91.

Arslan, S., and T.S. Colvin. 1999. Laboratory performance of a yield monitor. Appl. Eng. Agric. 15:189-195.

Avery, T.E., and G.L. Berlin. 1992. Fundamentals of remote sensing and airphoto interpretation. 5th ed. Macmillan, New York.

Baret, F., G. Guyot, and D.J. Major. 1989. TSAVI: A vegetation index which minimizes soil brightness effects on LAI and APAR estimation. p. 1355-1358. In Proc. IGARRS '89 Can. Symp. Remote Sensing, 12th, Vancouver, BC, Canada. 10-14 July 1989.

Blackmer, T.M., and J.S. Schepers. 1995. Use of a chlorophyll meter to monitor nitrogen status and schedule fertigation for corn. J. Prod. Agric. 8:56-60.

Blackmer, T.M., J.S. Schepers, and G.E. Varvel. 1994. Light reflectance compared with other nitrogen stress measurements in corn leaves. Agron. J. 86:934-938.

Buschmann, C., and E. Nagel. 1993. In spectroscopy and internal optics of leaves as basis for remote sensing of vegetation. Int. J. Remote Sens. 14:711-722.

Colwell, R.M. 1956. Determining the prevalence of certain cereal crop diseases by means of aerial photography. Hilgardia 26:223-286.

Gitelson, A.A., Y.J. Kaufman, and M.N. Merzlyak. 1996. Use of a green channel in remote sensing of global vegetation from EOSMODIS. Remote Sens. Environ. 58:289-298.

Gitelson, A.A., and M.N. Merzlyak. 1994. Spectral reflectance changes associated with autumn senescence of Aesculus hippocastanum L. and Acer platanoides L. leaves. Spectral features and relation to chlorophyll estimation. J. Plant Physiol. 143:286-292.

Huete, A.R. 1988. A soil-adjusted vegetation index (SAVI). Remote Sens. Environ. 25:295-309.

Jackson, R.D., T.R. Clark, and M.S. Moran. 1992. Bidirectional calibration results for 11 Spectralon and $16 \mathrm{BaSO} 4$ reference reflectance panels. Remote Sens. Environ. 40:231-239.

Jordan, C.F. 1969. Derivation of leaf area index from quality of light on the forest floor. Ecology 50:663-666.

Lark, R.M., J.V. Stafford, and H.C. Bolam. 1997. Limitations on the spatial resolution of yield mapping for combinable crops. J. Agric. Eng. Res. 66:183-193.

Littel, R.C., G.A. Miliken, W.W. Stroup, and R.D. Wolfinger. 1996. SAS systems for mixed models. SAS Inst., Cary, NC.

Moran, M.S., Y. Inoue, and E.M. Barnes. 1997. Opportunities and limitations for image-based remote sensing in precision crop management. Rem. Sens. Environ. 61:319.

[NRC] National Research Council. 1997. Precision agriculture in the 21st century: Geospatial and information technologies in crop management. Rep. 59-0700-4-139. NRC, Washington, DC.

Peterson, T.A., T.M. Blackmer, D.D. Francis, and J.S. Schepers. 1993. Using a chlorophyll meter to improve $\mathrm{N}$ management. In Nebguide G93-1171A. Coop. Ext. Serv., Univ. of Nebraska, Lincoln.

Ramsey, R.D., A. Falconer, and J.R. Jensen. 1995. The relationship between NOAA-AVHRR NDVI and ecoregions in Utah. Remote Sens. Environ. 53:188-198.

Ritchie, S.W., J.J. Hanway, and G.O. Benson. 1997. How a corn plants develops. Spec. Publ. 48. Iowa State Univ. Coop. Ext. Serv., Ames.

Roderick, M., R. Smith, and S. Cridland. 1996a. The precision of the NDVI derived from AVHRR observations. Remote Sens. Environ. 56:57-65.

Roderick, M., R. Smith, and G. Lodwick. 1996b. Calibrating long-term AVHRR-derived NDVI imagery. Remote Sens. Environ. 58:1-12.

Rondeaux, G., M. Steven, and F. Baret. 1996. Optimization of soiladjusted vegetation indices. Remote Sens. Environ. 55:95-107.

Schepers, J.S. 1994. New diagnostic tools for tissue testing. Commun. Soil Sci. Plant Anal. 25:817-826.

Schepers, J.S., T.M. Blackmer, W.W. Wihlelm, and M. Resende. 1996. Transmittance and reflectance measurements of corn leaves from plants differing in nitrogen and water supply. J. Plant Physiol. 148: 523-529.

Schepers, J.S., D.D. Francis, M.F. Vigil, and F.E. Below. 1992. Comparison of corn leaf nitrogen concentration and chlorophyll meter readings. Commun. Soil Sci. Plant Anal. 23:2173-2187.

Sellers, P.J. 1985. Canopy reflectance, photosynthesis, and transpiration. Int. J. Remote Sens. 6:1335-1372.

Sellers, P.J. 1987. Canopy reflectance, photosynthesis, and transpiration: II. The role of biophysics in the linearity of their interdependence. Remote Sens. Environ. 21:143-183.

Teillet, P.M. 1992. An algorithm for the radiometric and atmospheric correction of AVHRR data in the solar reflective channels. Remote Sens. Environ. 41:185-195.

Tucker, C.J. 1979. Red and photographic infrared linear combinations for monitoring vegetation. Remote Sens. Environ. 8:127-150.

Varvel, G.E., J.S. Schepers, and D.D. Francis. 1997. Ability for inseason correction of nitrogen deficiency in corn using chlorophyll meters. Soil Sci. Soc. Am. J. 61:1233-1239.

Wade, G., R. Mueller, P. Cook, and P. Doraiswamy. 1994. AVHRR map products for crop condition assessment: A geographic information systems approach. Photogramm. Eng. Rem. Sens. 60:11451150.

Wiegand, C.L., A.J. Richardson, D.E. Escobar, and A.H. Gerbermann. 1991. Vegetation indices in crop assessments. Rem. Sens. Environ. 35:105-119.

Wiegand, C.L., D.E. Richardson, D.E. Escobar, and J.H. Everitt. 1994. Photographic and video graphic observations for determining and mapping the response of cotton to soil salinity. Rem. Sens. Environ. 49:212-223. 